\title{
Erratum to: CONCEPTT: Continuous Glucose Monitoring in Women with Type 1 Diabetes in Pregnancy Trial: A multi-center, multi-national, randomized controlled trial - Study protocol
}

Denice S. Feig ${ }^{1,2,3,17^{*}}$, Elizabeth Asztalos ${ }^{4,13}$, Rosa Corcoy ${ }^{5,6}$, Alberto De Leiva ${ }^{5,6}$, Lois Donovan ${ }^{7}$, Moshe Hod ${ }^{8}$, Lois Jovanovic ${ }^{9}$, Erin Keely ${ }^{10}$, Craig Kollman ${ }^{11}$, Ruth McManus ${ }^{12}$, Kellie Murphy ${ }^{1,2}$, Katrina Ruedy ${ }^{11}$, J. Johanna Sanchez ${ }^{4,13}$, George Tomlinson ${ }^{14}$, Helen R. Murphy ${ }^{15,16}$ and on behalf of the CONCEPTT Collaborative Group

\section{Erratum}

After publication of the original article [1], it came to the authors' attention that an incorrect affiliation was inadvertently added in the Acknowledgements section for the CONCEPTT Collaborative Group. The authors would like to amend the following statement in the CONCEPTT Collaborative Group section as follows: The correct affiliation for Julia Lowe and Anna Rogowsky should read Sunnybrook Health Sciences Centre, Toronto.

\section{Author details}

${ }^{1}$ Mt. Sinai Hospital, Toronto, Ontario, Canada. ${ }^{2}$ Lunenfeld-Tanenbaum Research Institute, Toronto, Ontario, Canada. ${ }^{3}$ Department of Medicine, University of Toronto, Toronto, Canada. ${ }^{4}$ Sunnybrook Health Sciences Centre, Toronto, Ontario, Canada. ${ }^{5} \mathrm{Hospital}$ de la Santa Creu i Sant Pau, Barcelona, Spain. ${ }^{6}$ CIBER-BBN, Zaragoza, Spain. ${ }^{7}$ University of Calgary, Calgary, Alberta, Canada. ${ }^{8}$ Helen Schneider Hospital for Women, Rabin Medical Center, Petah Tikva, Israel. ${ }^{9} 30-1$ Barranca Avenue, Santa Barbara, CA, USA. ${ }^{10}$ The Ottawa Hospital, Riverside Campus, Ottawa, Ontario, Canada. ${ }^{11}$ Jaeb Center For Health Research, Tampa, FL, USA. ${ }^{2}$ St. Joseph Health Care London, London, Ontario, Canada. ${ }^{13}$ Sunnybrook Research Institute, Toronto, Ontario, Canada. ${ }^{14}$ University Health Network, Toronto General Hospital, Toronto, Ontario, Canada. ${ }^{15}$ Institute of Metabolic Science, Cambridge University Hospitals NHS Foundation Trust, Cambridge, UK. ${ }^{16}$ Norwich Medical School, University of East Anglia, Norwich, UK. ${ }^{17}$ Department of Medicine, Leadership Sinai Centre for Diabetes, Mt. Sinai Hospital, 60 Murray St. \#5027, Toronto, Ontario M5T 3L9, Canada.

Received: 18 August 2016 Accepted: 18 August 2016 Published online: 26 August 2016

\section{Reference}

1. Feig DS, Asztalos E, Corcoy R, De Leiva A, Donovan L, Hod M, Jovanovic L, Keely E, Kollman C, McManus R, Murphy K, Ruedy K, Sanchez JJ, Tomlinson $\mathrm{G}$, Murphy HR, on behalf of the CONCEPTT Collaborative Group. CONCEPTT: Continuous Glucose Monitoring in Women with Type 1 Diabetes in Pregnancy Trial: A multi-center, multi-national, randomized controlled trial Study protocol. BMC Pregnancy Childbirth. 2016;16:167.

\footnotetext{
* Correspondence: d.feig@utoronto.ca

${ }^{1}$ Mt. Sinai Hospital, Toronto, Ontario, Canada

'Lunenfeld-Tanenbaum Research Institute, Toronto, Ontario, Canada

Full list of author information is available at the end of the article
}

\footnotetext{
Submit your next manuscript to BioMed Central and we will help you at every step:

- We accept pre-submission inquiries

- Our selector tool helps you to find the most relevant journal

- We provide round the clock customer support

- Convenient online submission

- Thorough peer review

- Inclusion in PubMed and all major indexing services

- Maximum visibility for your research
}

Submit your manuscript at www.biomedcentral.com/submit 